American Journal of Pharmaceutical Education 2016; 80 (10) Article 165.

\title{
RESEARCH
}

\section{Qualitative Evaluation of a Practice-based Experience Pilot Program for Master of Pharmacy Students in Scotland}

\author{
Gillian Hendry, MRes, ${ }^{\text {a }}$ Philip Winn, SRPharmS, ${ }^{\mathrm{b}}$ Sally Wiggins, $\mathrm{PhD},{ }^{\mathrm{c}}$ Christopher J. Turner, $\mathrm{PhD}^{\mathrm{d}}$ \\ ${ }^{a}$ School of Psychological Sciences and Health, University of Strathclyde, Glasgow, Scotland \\ ${ }^{\mathrm{b}}$ Strathclyde Institute of Pharmacy and Biomedical Sciences, University of Strathclyde, Glasgow, Scotland \\ ${ }^{c}$ Department of Behavioural Science and Learning, Linköping University, Linköping, Sweden. \\ ${ }^{\mathrm{d}}$ Retired but formerly with Skaggs School of Pharmacy and Pharmaceutical Sciences, University of Colorado Anschutz \\ Medical Campus, Aurora, Colorado \\ Submitted August 18, 2015; accepted February 9, 2016; published December 25, 2016.
}

\begin{abstract}
Objective. To determine the views of pharmacists in central Scotland regarding experiential education for MPharm students.

Methods. A thematic analysis was completed by Ms. Gillian Hendry and Dr. Sally Wiggins of interviews conducted with ten practicing pharmacists paired with first-year master of pharmacy (MPharm) students during the 2011-2012 academic year. Relevant comments from the interviews were manually sorted in a Microsoft Excel spreadsheet to bring similarly themed material together to facilitate the identification and naming of recurring themes and subthemes.

Results. The pharmacists were unanimous in their opinion that experiential education was valuable for MPharm students and, in particular, that it helped students to develop self-confidence. The pharmacists derived personal satisfaction in developing mentor/mentee relationships with students. They also recognized the value that students provided to the workforce as well as the educational value to themselves in supervising students. The participants' primary dissatisfaction was that the pharmacy workflow limited the time they could spend mentoring students.

Conclusion. The results provide guidance to the academic community and the pharmacy practice community in the United Kingdom (UK) regarding the design and integration of experiential education courses in MPharm degree programs.
\end{abstract}

Keywords: MPharm program, accreditation standards, experiential education, practice-based education, preceptors.

\section{INTRODUCTION}

The entry-to-practice training of pharmacists in the United Kingdom normally involves four years of study in an accredited undergraduate MPharm degree program followed by a year of experiential education known as the preregistration year. ${ }^{1}$ Preregistration training is similar in its length and time requirements to advanced pharmacy practice experience (APPE) training in the United States. However, it differs in that it is normally completed at one practice site with one preceptor (preceptor is the term used in North America to describe practitioners who host and supervise students), whereas APPE training exposes students to varied forms of pharmacy practice with multiple preceptors in multiple practice sites.

A further difference is that the General Pharmaceutical Council ( $\mathrm{GPhC}$ ) rather than the universities oversees

Corresponding Author: Christopher J. Turner, 21811 East

Berry Lane, Centennial, CO 80015. Tel: 720-870-9599.

E-mail: Christopher.Turner@ucdenver.edu the preregistration year. The GPhC replaced the Royal Pharmaceutical Society of Great Britain as the licensing body for pharmacists, pharmacies, and pharmacy technicians in England, Scotland, and Wales in 2010. The GPhC is responsible for establishing MPharm degree accreditation standards and for holding UK pharmacy schools accountable for meeting those standards.

Historically, experiential education (known as clinical placement education in the United Kingdom) was not emphasized in the MPharm degree program, ${ }^{1}$ but in 2011 revised GPhC MPharm degree accreditation standards introduced the requirement for students to have experiential education increasing year-on-year in working with patients, carers, and other health care professionals. ${ }^{2}$ The standards list 57 identical educational outcomes for both the MPharm and preregistration programs, but they differ with respect to level of competency. For example, for educational outcome 10.2.2h: "Optimize treatment for individual patient needs in collaboration with the prescriber," MPharm students must be judged competent to 


\section{American Journal of Pharmaceutical Education 2016; 80 (10) Article 165.}

the level "Shows how" whereas preregistration students must be judged competent to the level "Does."

Concomitantly with publication of the new GPhC accreditation standards, the UK Modernizing Pharmacy Careers Professional Board (MPCPB) published a proposal to integrate MPharm and preregistration training into a five-year curriculum that would be jointly owned, planned, and delivered by universities and employers, with emphasis on work-based learning and contact with patients beginning early in the program. ${ }^{3}$ The increased emphasis on experiential education in the United Kingdom greatly increases the number of pharmacists and practice sites needed to host MPharm students.

We reported in a previous paper that there is substantial support for MPharm experiential education from pharmacists, particularly community pharmacists, in central Scotland. ${ }^{4}$ In brief, 39 volunteer first-year MPharm students in the Strathclyde Institute of Pharmacy and Biomedical Sciences (SIPBS) were paired with 38 volunteer pharmacists in the 2011-2012 academic year for two 3 -hour practice-site visits per month. The pharmacists were asked to establish mentor/mentee relationships with their students, to integrate their students into the pharmacy workflow, and to use their best judgment in giving students a steadily increasing breadth and depth of workplace experience. The objective, with respect to curriculum development and establishing educational outcomes, was to establish the activities that the pharmacists thought appropriate for first-year MPharm students.

The list of supervised responsibilities given to students is reported in our previous paper but ranged from simple tasks such as stock control to more complex tasks including dispensing-related activities, follow-up telephone calls to patients, completing diabetes and blood pressure checks, and advising patients on self-care issues. ${ }^{4}$ Surveyed in spring 2012, every pharmacist stated their student was welcome to return in the 2012-2013 academic year and 29 agreed to accept a second student. Nine of 12 participating chain community pharmacy companies asked for program expansion and 12 community pharmacy companies that did not participate in 20112012 asked to join in 2012-2013. In the time available to the investigators in 2012-2013 and with the encouragement of their employers, 89 pharmacists who did not participate in 2011-2012 were interviewed. All but one expressed willingness to host MPharm students, and, collectively, offered places for 167 students. Hospital pharmacists expressed support for practice-based experience in the MPharm program, but most declined to participate, citing workplace pressure.

We report here the results of a qualitative research study involving the pharmacists who participated in our previous study. The primary goal of the study was to provide guidance to SIPBS for the inclusion of experiential education in its MPharm degree program. The primary objectives were to validate the findings reported in our previous paper and to identify the reasons why the participating pharmacists supported the concept of experiential education in the MPharm program.

\section{METHODS}

The participants were pharmacists practicing in central Scotland (within a reasonable travelling distance from SIPBS for students) who participated in our previous study. ${ }^{4}$ They were contacted by the authors of that study to explain the purpose of the qualitative evaluation, to provide assurance of the voluntary and confidential nature of the evaluation, and to ask permission for them to be contacted by a researcher serving as an external investigator from the University of Strathclyde School of Psychological Sciences and Health (USSPSH) under the supervision of her USSPSH faculty supervisor. The interviews with pharmacists who agreed to participate were recorded and subsequently transcribed into a written format. Each participant was assigned a pseudonym and any other identifiable features were omitted in the transcription process. The University of Strathclyde School of Psychological Sciences and Health Ethics Committee approved the study, including the information sheet given to each participant and the written consent form each participant was required to sign prior to interview. The consent form stated that the participants had the right to withdraw from the study at any time.

Ten pharmacists (seven female and three male; eight community and two hospital pharmacists) were interviewed at their place of work and every participant was asked the same questions (please see Analytic Procedure below for justification of the sample size). Interviews totaled 357 minutes, ranging from 17 minutes to 55 minutes, with an average length of 36 minutes. The interviews varied in length because some of the pharmacists needed to attend to workplace issues during the interviews. Also, the pharmacists' responses to the interviewer's questions varied in length, and it was sometimes necessary for the interviewer to ask supplemental questions to clarify issues.

The interviewees were asked to comment on the value of experiential education to the students' education and the advantages and disadvantages to themselves in hosting the students. Transcripts of the interviews are available on request from the corresponding author. The study constituted a yearlong sabbatical project for Dr. Christopher Turner and was supported by the University of Strathclyde Education Excellence Fund. 


\section{American Journal of Pharmaceutical Education 2016; 80 (10) Article 165.}

A thematic analysis was applied to the data to identify, analyze, and report recurring themes relevant to the study. ${ }^{5}$ Data (phrases, sentences, etc, containing information relevant to the study) were copied from each transcript to a Microsoft Excel spreadsheet and manually sorted by Ms. Gillian Hendry to bring similarly themed material together to facilitate the identification and naming of recurring themes and subthemes in the 10 transcripts. The transcripts, the data abstracted from the transcripts, and the identified recurrent themes and subthemes were reviewed by Dr. Sally Wiggins to validate the initial analysis. There is no established ideal sample size when using thematic analysis. Most qualitative studies use the concept of saturation, the point at which no new information or themes are observed in the data. ${ }^{6-8}$ Saturation was deemed to have occurred in this study after 10 pharmacists were interviewed.

\section{RESULTS}

The themes and subthemes listed in Table 1 were identified from the interview transcripts. Because of space constraints, the analytical focus was on those themes deemed most influential for pharmacists in deciding whether to host and mentor students (themes $5 \mathrm{a}, 1 \mathrm{~b}$, and $1 \mathrm{c}$ ).

\section{Educational Value for Students (Theme 5a)}

The pharmacists described the educational value of the students' experiences primarily by referring to their own training. They emphasized how much they would have appreciated a similar opportunity when they were students and that they felt they had missed out by not getting hands-on pharmacy experience until later in their

Table 1. Themes and Subthemes Identified from Pharmacist Interviews

1. Involvement

a. Reasons for involvement

b. Advantages of involvement

c. Disadvantages of involvement

2. Experience in education

a. Reasons for involvement

b. Advantages of involvement

c. Disadvantages of involvement

3. Success

a. Factors deeming project successful

b. Student progression

4. Continuity

a. Continuation in project

b. Ideas for improvement of project

c. How to get others involved/advice to newcomers

5. Finding value

a. Educational value for students

b. Value of mentor/mentee relationship training. They spoke about how valuable hands-on experience is and the importance of giving students opportunities to gain experience (Appendix 1; quotations 1, 2).

The pharmacists agreed that the students made obvious progress over the course of their two 3-hour visits per month and that, in their minds, was the primary proof of the educational value of the visits (please see our previous paper for further information on the number of student visits). ${ }^{4}$ The concept of confidence was raised by all the pharmacists interviewed, with all indicating that developing confidence is an important part of the educational process (Appendix 1; quotation 3).

\section{Advantages and Disadvantages for Pharmacists (Themes 1b, 1c)}

The pharmacists found value in mentoring students, and in some instances the mentor/mentee concept was a primary reason for involvement (Appendix 1, quotation 4). Their reason for valuing the mentor/mentee relationship was based on their own experiences of either having or not having a mentor when they were students, and on their definition of a mentor as someone who is supportive and encourages learning (Appendix 1, quotation 5).

The pharmacists found value in the workforce provided by the students (Appendix 1: Quotation 6). However, they were sensitive to students' learning needs and took advantage of learning opportunities when they arose (Appendix 1, quotation 7). The pharmacists found value in the opportunity for workforce recruitment and for their own continuous professional development (Appendix 1, quotations 8,9$)$. The primary challenge for the pharmacists was to balance their workflow responsibilities with their interest in the students' education (Appendix 1, quotation 10).

The participants agreed unanimously that experiential education is essential. Most of the participants stressed how lucky the current students were in getting the opportunity to experience work in a pharmacy as they themselves did not have the experience at university. Encouragingly, all those interviewed agreed that they would be happy to continue with the project; however, the pharmacists interviewed only represented approximately a quarter of the pharmacists involved in the pilot program. ${ }^{4}$ While they would be happy to continue, some pharmacists stated they would not be able to contribute or accept anything more (such as more students or more placements) because of time constraints. No one said they had any intention of withdrawing from the project, not even those who reported less positive experiences with their students.

\section{DISCUSSION}

This study demonstrates a successful collaboration between an American university and two academic units 


\section{American Journal of Pharmaceutical Education 2016; 80 (10) Article 165.}

in a Scottish university regarding the education of pharmacy students. There are multiple examples of international collaboration between pharmacy educators. For example, SIPBS has a formalized teaching agreement with the International Medical University pharmacy school in Malaysia and the University of Colorado has a formalized teaching agreement with the Future University of Egypt pharmacy school. The American Journal of Pharmaceutical Education itself represents international collaboration. ${ }^{9}$ Examples of other forms of international collaboration include sabbatical experiences, ${ }^{10}$ direct patient care activities for students in advanced pharmacy practice experience training, ${ }^{11}$ exchange student experiences, ${ }^{12}$ residency program accreditation, ${ }^{13}$ development of pharmacy practice, ${ }^{14,15}$ and the publication of reports and position papers. ${ }^{16,17}$

However, to the best of our knowledge, the collaboration reported in this paper and our previous paper is the first to use experience gained in the United States to help the development of introductory pharmacy practice experience (IPPE) education in another country. Furthermore, we are unaware of any other studies that have employed an external (nonpharmacy school) academic unit to validate and extend the findings of an international IPPE study.

The results of this study validate the findings reported in our previous paper that pharmacists in central Scotland, particularly community pharmacists, are willing to support MPharm experiential education. ${ }^{4}$ The fact that the pharmacists who offered IPPE training sites in 2012-2013 for 235 MPharm students represented only $14 \%$ of the community pharmacies in central Scotland is encouraging. The results complement the findings of our previous paper ${ }^{4}$ by providing further insight into why pharmacists chose to participate in the pilot MPharm experiential education program. The knowledge that all the interviewees wished they had been given a similar opportunity to gain practice experience when they were students will be useful to SIPBS and to other pharmacy schools in the United Kingdom and elsewhere in preceptor recruitment.

Preceptor recruitment will also be facilitated by the finding that the pharmacists saw value in and derived selfsatisfaction from establishing mentor/mentee relationships with students and seeing them gain knowledge, skill, and self-confidence in participating in everyday pharmacy operations. The pilot program was not designed to demonstrate long-term sustainability of pharmacist support for experiential education in the MPharm program. However, with respect to sustainability, it is important that the pharmacists saw business advantages and continuous professional development opportunities for themselves in hosting MPharm students. Some preceptors offered to pay the students for their work, and none asked for financial remuneration, which is important in light of limited pharmacy school resources.

The findings of the study are important for pharmacy schools in England, Scotland, and Wales because GPhC MPharm accreditation standards do not mandate a minimum number of hours of experiential education. ${ }^{2}$ In the absence of specific direction by the GPhC standards, the findings provide evidence that it would be advantageous to pharmacy schools in England, Scotland, and Wales to design MPharm experiential education courses with sufficient contact hours for pharmacy practitioners to establish and maintain mentor/mentee relationships with their students and to receive the other workplace benefits reported in this and our previous paper. ${ }^{4}$ MPharm experiential courses designed with insufficient contact hours to achieve those outcomes probably would not be sustainable unless preceptors were given financial remuneration for their work. Echoing the UK MPCPB recommendation for MPharm programs jointly owned, planned, and delivered by universities and employers, ${ }^{3}$ experiential education courses are more likely to be sustainable if they meet the business, humanistic, and professional needs of the practice community in addition to the educational needs of students.

Experiential education courses that meet the business, humanistic, and professional needs of the practice community have the potential to optimize student learning. Adult learning theory holds that people learn best when integrated in the workplace (ie, given purposeful tasks and responsibilities) within a structure that encourages learning. ${ }^{18-22}$ Acquisition of content knowledge is secondary to the approach to learning ${ }^{23}$ as evidenced by multiple examples of pharmacy students at all stages in their education successfully undertaking responsibilities, including direct patient care responsibilities under preceptor supervision. ${ }^{24-30}$ Competency develops slowly over time, ${ }^{19,31-34}$ and, accordingly, students must be given continuous opportunity from the earliest days of their pharmacy education to gain experience dealing with the limitless variety of challenges presented by pharmacy practice if they are to be practice ready at licensure.

Given the results of this study and the results reported in our previous paper, it is advantageous to UK pharmacy educators that the framework for clinical community pharmacy services in the United Kingdom is well advanced. For example, licensed community and other pharmacists in the United Kingdom can acquire autonomous prescribing rights for any medical condition within their clinical competence ${ }^{1,35}$ and supplementary prescribing rights with respect to clinical management plans in 


\section{American Journal of Pharmaceutical Education 2016; 80 (10) Article 165.}

a voluntary partnership involving a patient and a physician or dentist. ${ }^{1,36}$ The National Health Service (NHS) Chronic Medication Service provides remuneration to pharmacists who council patients regarding their use of chronic medications and who establish and monitor care plans for those patients. ${ }^{37}$ The NHS provides remuneration in the Minor Ailment Scheme to pharmacists who provide advice to patients with minor illnesses or ailments. ${ }^{38}$ There are multiple other remunerated community pharmacy-based clinical programs including anticoagulation management, vaccination, and smoking cessation services. ${ }^{39-42}$

At present, the required training to deliver clinical pharmacy services is only offered to licensed pharmacists. However, the need to incorporate appropriate training in the MPharm program such that students are competent to offer clinical services at graduation has been recognized as one of the challenges facing pharmacy educators in the United Kingdom. ${ }^{1}$ A full description of those challenges is beyond the scope of this paper. Nonetheless, the value of experiential education to adult learners described above, the sustainability of experiential education engendered by integrating students into the pharmacy workforce, and the forces envisioning a 5-year MPharm curriculum jointly owned, planned, and delivered by universities and employers ${ }^{3}$ will be crucial with respect to curriculum design, to the choice of educational methods and learning outcomes, and to program and student assessment.

Further challenges for UK pharmacy educators include the relative lack of full-time faculty members with clinical specialty credentials in UK pharmacy schools. ${ }^{1}$ The implication is that UK pharmacy schools will need to rely heavily on clinical specialists in the practice community for curriculum design, school-based teaching, and school-based assessment of educational outcomes, in addition to depending on the practice community to provide experiential education. For example, the evidence-based teaching methods recommended for pharmacy education include small group work and reflection, including written reflection. ${ }^{23}$ The workforce logistics associated with facilitating small group work and providing feedback on reflective writing ${ }^{43}$ would fall heavily on the practice community. In addition, the prevalence of clinical pharmacy services in community and hospital pharmacies needs to be considered and, if necessary, grant-funded faculty initiatives need to be undertaken to help practitioners implement clinical services as demonstrated in the United States. ${ }^{28,44}$ With further respect to logistics, pharmacy schools in England, Wales and Scotland will need to take advantage of the existing infrastructure in the United Kingdom for matching students with experiential practice sites. ${ }^{45,46}$ Collaboration between pharmacy schools and other programs to develop and provide preceptor training is likely to be helpful as demonstrated in the United States. ${ }^{47}$

\section{CONCLUSIONS}

The study represents a successful international collaboration between two universities regarding entry-topharmacy practice curriculum design. The results provide insight into why pharmacy practitioners in central Scotland are willing to support experiential education in the MPharm program. They give guidance to UK pharmacy educators with respect to the design, implementation, operation, and assessment of sustainable experiential education courses that meet GPhC MPharm accreditation standards.

\section{ACKNOWLEDGMENTS}

This work was made possible with the help and encouragement of multiple individuals and health care entities. The authors, in particular, wish to thank the students and pharmacists who participated in the pilot project; Professor Graham Coombs who was SIPBS Head of Institute when the project was first conceived; Niall Coggans, Simon Mackay, and Anne Boyter who were SIPBS Head of the MPharm Program during the pilot project; Professor Norman Lannigan, NHS Greater Glasgow and Clyde; Community Pharmacy Scotland; NHS Education for Scotland; and the National Pharmacy Association. The study was supported by the University of Strathclyde Education Excellence Fund.

\section{REFERENCES}

1. Sosabowski MH, Gard PR. Pharmacy education in the United Kingdom. Am J Pharm Educ. 2008;72(6):Article 130

2. General Pharmaceutical Council. Future pharmacists: standards for the initial education and training of pharmacists. http://www. pharmacyregulation.org/sites/default/files/Standards $\% 20$ for $\% 20$ the $\%$ 20initial $\% 20$ education $\% 20$ and $\% 20$ training $\% 20$ of $\% 20$ pharmacists.pdf Accessed December 15, 2016.

3. Smith A, Darracott R. Modernizing pharmacy careers programme: review of pharmacist undergraduate training and proposals for reform. https://www.hee.nhs.uk/sites/default/files/documents/ Pharmacist-pre-registration-training-proposals-for-reform.pdf Accessed December 15, 2016.

4. Winn P, Turner CJ. Description and evaluation of an MPharm practice-based experience pilot program. Am J Pharm Educ. 2016;80(9): Article 151.

5. Braun V, Clarke V. Using thematic analysis in psychology. Qual Res Psychol. 2006;3(2):77-101.

6. Guest G, Bunce A, Johnson L. How many interviews are enough? An experiment with data saturation and variability. Field Meth. 2006;18(1):59-82.

7. Willig C. Introducing Qualitative Research in Psychology. $3^{\text {rd }}$ ed. New York, NY: McGraw-Hill Education; 2013. 


\section{American Journal of Pharmaceutical Education 2016; 80 (10) Article 165.}

8. Fugard AJB, Potts HWW. Supporting thinking on sample sizes for thematic analyses: a quantitative tool. Int J Soc Res Meth. 2015; 18(6):669-684.

9. DiPiro JT. Our international connections. Am J Pharm Educ. 2006;70(3):Article 61

10. Soltis D. Personal and professional growth through an international sabbatical experience. Am J Pharm Educ. 2013;77(1): Article 2.

11. Pastakia SD, Vincent WR III, Manji I, Kamau E, Schellhase EM. Clinical pharmacy consultations provided by American and Kenyan pharmacy students during an acute care advanced pharmacy practice experience. Am J Pharm Educ. 2011;75(3):Article 42.

12. Davey AK, Grant GD, Anoopkumar-Dukie S. Academic performance and personal experience of local, international, and collaborative exchange students enrolled in an Australian pharmacy program. Am J Pharm Educ. 2013;77(7):Article 148.

13. Al-Qadheeb NS, Alissa DA, Al-Jedai A, Ajlan A, Al-Jazairi AS. The first international residency program accredited by the American Society of Health-System Pharmacists. Am J Pharm Educ. 2012;76(10): Article 190.

14. Coombes ID, Fernando G, Wickramaratne DBM, et al. Collaborating to develop clinical pharmacy teaching in Sri Lanka. Pharm Educ. 2013;13(1):29-35.

15. Bushell MJA, Morrissey H, Waidyarathne, Zawahir S, Ball P. Sri Lankan perspectives on pharmacist-administered vaccinations. Pharmaceut Reg Affairs. 2015;4(1):Article 135.

16. Kehrer JP, Schindel TJ, Mann HJ. Cooperation in pharmacy education in Canada and the United States. Am J Pharm Educ. 2010;74(8):Article 142.

17. Anderson C, Brock T, Bates I, et al. Transforming health professional education. Am J Pharm Educ. 2011;75(2):Article 22. 18. Beck DE, Thomas SG, Janer AL. Introductory practice experiences: a conceptual framework. Am J Pharm Educ. 1996;60(2):122-131.

19. Johnson JL. Self-authorship in pharmacy education. Am J Pharm Educ. 2013;77(4):Article 69

20. Blackwell A, Bowes L, Harvey L, Hesketh AJ, Knight PT. Transforming work experience in higher education. Brit Educ Res J. 2001;27(3):269-285.

21. Franz JM. A Pedagogical Model of Higher Education/Industry Engagement for Enhancing Employability and Professional Practice. In Proceedings Work Integrated Learning (WIL): Transforming Futures, Practice...Pedagogy. . Partnerships. Manly, Sydney, Australia; 2008:164-169.

22. Wenrich MD, Jackson MB, Wolfhagen I, Ramsey PG, Scherpbier AJJ. What are the benefits of early patient contact? A comparison of three preclinical patient contact settings. BMC Med Educ. 2013;13:80.

23. Speedie MK, Baldwin JN, Carter RA, Raehl CL, Yanchick VA, Maine LL. Cultivating "Habits of Mind" in the scholarly pharmacy clinician: report of the 2011-12 Argus Commission. Am J Pharm Educ. 2012;76(6):Article S3.

24. Freml JM, Farris KB, Fang G, Currie J. Iowa Priority's brown bag medication reviews: a comparison of pharmacy students and pharmacists. Am J Pharm Educ. 2004;68(2):Article 50.

25. Haggerty SA, Cerulli J, Zeolla MM, Cottrell JS, Weck MB, Faragon JJ. Community pharmacy target intervention program to improve aspirin use in persons with diabetes. $J$ Am Pharm Assoc. 2005;45(1):17-22.

26. Turner CJ, Ellis S, Giles J, et al. An introductory pharmacy practice experience emphasizing student-administered vaccinations. Am J Pharm Educ. 2007;71(1):Article 3.
27. Dalal K, McCall KL, Fike DS, Horton N, Allen A. Pharmacy students provide care comparable to pharmacists in an outpatient anticoagulation setting. Am J Pharm Educ. 2010;74(8):Article 139. 28. Nuffer W, McCollum M, Ellis SL, Turner CJ. Further development of pharmacy student-facilitated diabetes management clinics. Am J Pharm Educ. 2012;76(3):Article 50.

29. Hata M, Klotz R, Sylvies R, et al. Medication therapy management services provided by student pharmacists. Am J Pharm Educ. 2012;76(3):Article 51.

30. Hardin HC, Hall AM, Roane TE, Mistry R. An advanced pharmacy practice experience in a student-staffed medication therapy management call center. Am J Pharm Educ. 2012;76(6):Article 110. 31. Guest CB, Regehr G, Tiberius RG. The life long challenge of expertise. Med Educ. 2001;35(1):78-81.

32. Duncan-Hewitt W. The development of a professional: reinterpretation of the professionalization problem from the perspective of cognitive/moral development. Am J Pharm Educ. 2005;69(1):Article 6.

33. Ericsson KA. The influence of experience and deliberate practice on the development of superior expert performance. In, The Cambridge Handbook of Expertise and Expert Performance. New York, NY: Cambridge University Press; 2006:683-703.

34. Mann K, Gordon J, MacLeod A. Reflection and reflective practice in health professions education: a systematic review. $A d v$ Health Sci Educ Pract. 2009;14(4):595-621.

35. General Pharmaceutical Council. Pharmacist independent prescriber. http://www.pharmacyregulation.org/education/ pharmacist-independent-prescriber Accessed December 15, 2016. 36. Department of Health. Supplementary prescribing. http:// webarchive.nationalarchives.gov.uk/+/www.dh.gov.uk/en/ Healthcare/Medicinespharmacyandindustry/Prescriptions/ TheNon-MedicalPrescribingProgramme/Supplementaryprescribing/ index.htm Accessed December 15, 2016.

37. NHS Inform. The NHS Chronic Medication Service at your local pharmacy. A service for people with a long-term condition. http://www. gov.scot/Resource/0043/00433677.pdf Accessed December 15, 2016). 38. NHS Scotland. The NHS Minor Ailment Service at your local pharmacy. Information for patients. http:/www.gov.scot/Resource/ Doc/362554/0122689.pdf Accessed December 15, 2016.

39. Pharmaceutical Services Negotiating Committee. About community pharmacy. http://psnc.org.uk/psncs-work/about-communitypharmacy/ Accessed December 15, 2016.

40. Boots. Winter flu jab services. https://www.boots.com/en/_1539793. Accessed December 15, 2016.

41. LloydsPharmacy. Vaccinations at LloydsPharmacy. http://www. lloydspharmacy.com/en/info/Vaccinations Accessed December 15, 2016.

42. NHS National Services Scotland. NHS smoking cessation services publication report. http://www.isdscotland.org/Health-Topics/ Public-Health/Publications/2014-05-27/2014-05-27-SmokingCessationReport.pdf. Accessed December 1, 2015.

43. Nuffer W, Vaughn J, Kerr K, et al. A three-year reflective writing program as part of introductory pharmacy practice experiences. Am J Pharm Educ. 2013;77(5):Article 100.

44. Turner CJ, Ellis S, Giles J, et al. A strategy to develop advanced pharmacy practice experiences. Am J Pharm Educ. 2007;71(3): Article 46.

45. NHS Education for Scotland. Preregistration pharmacist scheme. http://www.nes.scot.nhs.uk/education-and-training/by-discipline/ pharmacy/pre-registration-pharmacist-scheme.aspx. Accessed December 15, 2016. 


\section{American Journal of Pharmaceutical Education 2016; 80 (10) Article 165.}

46. NHS Pre-registration Trainee Pharmacist Training. Recruitment of NHS pre-registration trainee pharmacists. Webcitation.org/6a00K4ie2. Accessed December 15, 2016.
47. McDuffie CH, Duke LJ, Stevenson TL, et al. Consortium-based approach to an online preceptor development program. Am J Pharm Educ. 2011;75(7):Article 135.

Appendix 1. Quotations from the pharmacist interviews

1. "I always felt that the one thing that was really missing (when I was a student) was the practical experience" (Pharmacist $10)$.

2. "What I would say to a colleague is, "go back to the start of your pre-reg. What did you actually know about practical pharmacy? Do you want the student to go through that" (Pharmacist 8).

3. "it's a question of confidence-building and her confidence is increasing quite appreciably - virtually in every visit" (Pharmacist 3)

4. "so this idea of just one-on-one mentoring....was really what appealed to me about it" (Pharmacist 7).

5. "personally I've had mentors and it's great having somebody rooting for you, em, so, I think that- that was positive" (Pharmacist 5)

6. "if we've got things that need to get done that maybe need an extra pair of hands... the student is there... might as well use them to do that, em, so it's handy for that type of thing (Pharmacist 2)

7. "if there are interesting things happening then I'll pull her off (take her away from whatever she's doing) and say, 'we'll, do this, eh, because I think it'll be of benefit- a benefit for you for later on"” (Pharmacist 3)

8. "the earlier you can get students interested in working with you and your business and get your eye open looking out for good students coming through, the better" (Pharmacist 4).

9. "It's educational for me, 'cause she'll ask me something, and I'll go, it's twenty years since I did that, I'll have to go away and look at it and refresh myself a bit." (Pharmacist 2).

10. "it (supervising the student) does obviously take up my time... but I do like to have some one-on-one time with her, so that is a burden on me and my workload" (Pharmacist 6). 